\title{
E-Cigarette Liquid Provokes Significant Embryotoxicity and Inhibits Angiogenesis
}

\author{
Anas A. Ashour 1,2,+®, Hashim Alhussain 2,+ , Umar Bin Rashid 1,2®, Labiba Abughazzah 1,2, \\ Ishita Gupta ${ }^{2} \mathbb{D}$, Ahmed Malki ${ }^{3}$, Semir Vranic ${ }^{1}$ (D) and Ala-Eddin Al Moustafa $1,2, * \mathbb{D}$ \\ 1 College of Medicine, QU Health, Qatar University, Doha 2713, Qatar; aa1510042@qu.edu.qa (A.A.A.); \\ ur1608109@qu.edu.qa (U.B.R.); la1605015@qu.edu.qa (L.A.); svranic@qu.edu.qa (S.V.) \\ 2 Biomedical Research Center, Qatar University, Doha 2713, Qatar; h.alhussain@qu.edu.qa (H.A.); \\ ishugupta28@gmail.com (I.G.) \\ 3 Biomedical Science Department, College of Health Sciences, QU Health, Qatar University, Doha 2713, Qatar; \\ ahmed.malki@qu.edu.qa \\ * Correspondence: aalmoustafa@qu.edu.qa; Tel.: +974-4403-7817 \\ + Both authors contributed equally to this article.
}

Received: 28 April 2020; Accepted: 23 May 2020; Published: 27 May 2020

\begin{abstract}
E-cigarette smoking (ECS) is a new method of tobacco smoking that is gaining popularity as it is thought to be a "healthy method" of tobacco consumption. The adverse outcomes of ECS on the respiratory and cardiovascular systems in humans have been recently demonstrated. Nevertheless, the effect of e-cigarette liquid (ECL) on the early stage of embryogenesis and angiogenesis has not been explored yet. Chicken embryo at 3 days of incubation and its chorioallantoic membrane (CAM) of 5 days were used to explore the outcome of ECL on the embryo. Real-time PCR was also employed to study the regulation of a set of key controller genes of embryogenesis as well as angiogenesis. Our study revealed that ECL exposure is associated with a high rate of mortality in embryos as around $70 \%$ of treated embryos, at 3 days of incubation, die after 5 days of exposure. Additionally, ECL inhibits angiogenesis of the CAM of 5 days of incubation by more than $30 \%$. These effects could be explained by the upregulation of ATF-3, FOXA2, INHBA, MAPRE-2, and RIPK-1, as well as the downregulation of SERPINA-4 and VEGF-C genes, which are important key controller genes of embryogenesis as well as angiogenesis. Our data suggest clearly that ECS can have dramatic toxic outcomes on the early stage of embryogenesis as well as angiogenesis. Accordingly, we believe that further studies to assess the effects of ECS on human health are essential.
\end{abstract}

Keywords: e-cigarettes; embryo; angiogenesis; toxicity; gene deregulations

\section{Introduction}

According to the World Health Organization [1], tobacco smoking accounts for 8 million deaths worldwide. It is estimated that there are 1.1 billion users of tobacco products worldwide accounting for $32 \%$ of the male and $7 \%$ of the female population [2]. There are various methods of tobacco consumption with the most common ones being cigarettes, electronic cigarettes (e-cigarettes), cigars, and water-pipe smoking. It has been well established that smoking causes a plethora of diseases including chronic obstructive pulmonary disease, cardiovascular events, rheumatoid arthritis, osteoarthritis, as well as multiple types of cancer such as upper respiratory, lung, bladder, renal, and pancreatic cancer [3].

E-cigarettes are new electronic devices that heat a nicotine or non-nicotine containing liquid with flavors stored in a refillable cartridge into a vapor to be inhaled [4]. E-cigarette smoking (ECS) was intensely advertised when released and was marketed as a healthier alternative to traditional cigarettes and a healthier device to switch to when quitting traditional smoking. Moreover, there are no clear 
legislations that restrict the use of ECS, such as imposing taxes, as it is not clearly defined. Additionally, in some countries ECS is not included in tobacco smoking products. Thus, it is not surprising that their prevalence is becoming higher, particularly among young adults [5,6]. Due to the absence of tobacco combustion, many of the toxins of traditional cigarettes such as carbon monoxide are absent. However, e-cigarette vapors have been known to contain low concentrations of some tobacco-derived chemicals such as carcinogenic nitrosamines, formaldehyde, and acrolein [7]. Furthermore, the fluid and vapor of e-cigarettes have been shown to contain heavy metals and silicate particles [8]. Moreover, materials used in flavoring and byproducts of the production process are associated with some serious adverse side effects [9]. Due to these reasons, questions have been raised on the health impact of e-cigarettes. Several reports have implicated e-cigarettes in common respiratory disorders such as acute bronchiolitis, acute eosinophilic pneumonia, and bilateral pleural effusions [10]. Furthermore, the aerosol produced by e-cigarettes is known to contain carcinogenic compounds such as nitrosamines and heavy metals. Consequently, concerns have also been raised on the cancer risk of long-term ECS. However, there is no definitive evidence suggesting a risk being present. It has also been shown that e-cigarettes may pose a cardiovascular risk, particularly to those who already have cardiovascular problems [11]. Lastly, second-hand exposure to e-cigarette vapors may also pose a risk to individuals according to a systematic review that has shown that second-hand exposure to e-cigarette smoke has the potential to lead to adverse health effects [12]. Most of these health risks are thought to be associated with ECS' effect on the inflammatory process, systemic dysfunction, and gene deregulation [13,14].

Although they have been anticipated as a safer substitute to conventional cigarettes, e-cigarettes are largely consumed by pregnant women. Thus, a few studies have investigated the impact of e-cigarettes on mice offspring. It was revealed that ECS during pregnancy adversely affects mice offspring, especially lung health and cognitive function $[15,16]$. With this in mind, studying the effect of e-cigarettes using a chicken embryo model could provide valuable information on the embryotoxicity of ECS as well as its effects on angiogenesis and embryos' survival, given the fact that no previous studies have investigated these effects on the chicken embryo model and angiogenesis before. Hence, the goal of this study is to investigate the outcome of e-cigarette liquid (ECL) on the early stages of the embryo and angiogenesis by exploring its effects on survival and the normal development of blood vessels in addition to a specific set of genes related to these biological events.

\section{Materials and Methods}

\subsection{E-Cigarette Liquid}

We used ECL as it is a convenient approach to obtain preliminary information about the toxic role of ECS, as ECL was used in other studies related to the outcome of ECS on the embryo [17]. ECL known as "Virginia Tobacco" with a nicotine concentration of $6 \mathrm{mg} / \mathrm{mL}$ in $70 \%, 30 \%$, and 15\% of propylene glycol (organic compound), vegetable glycerin, and fruit flavor, respectively, (E-Lixir, Montreal, QC, Canada) was chosen, since "Virginia tobacco" of $6 \mathrm{mg} / \mathrm{mL}$ nicotine is one of the most popular ECLs used by young people in Canada and Qatar. The liquid was stored in a dark cabinet at a temperature of $4{ }^{\circ} \mathrm{C}$ as recommended by the manufacturer. Based on our previous work, we used a final concentration of $2 \mathrm{mg} / \mathrm{mL}$ of nicotine [17-19]; the liquid was mixed with PBS (Qiagen, Toronto, ON, Canada) to obtain the desired concentration. This study was approved by the Institutional Biohazard Committee of Qatar University (QU-IBC) on 22 May 2019 (number: 2019/032).

\subsection{Embryos and In Ovo E-Cigarette Treatment}

A total of 97 White Leghorn chicken embryos were fertilized and incubated in similar conditions. Embryos were either treated with 30 or $60 \mu \mathrm{g}$ suspension of final nicotine concentration from ECL dissolved in PBS. The final concentrations of 30 and $60 \mu \mathrm{g}$ of nicotine were used based on our recent investigation of water-pipe smoking on embryo and cancer cells as well as other investigations related to the outcome of ECL on the embryo [17-19]. Control embryos were treated with PBS alone. From these 
embryos, 25 were treated at day 5 of incubation and observed for $48 \mathrm{~h}$ before being examined for the effect of ECL on angiogenesis; while, 72 embryos were exposed at day 3 of incubation and observed for another 5 days for survival analysis. All embryos that survived till 8 days of age were sacrificed. Autopsies from brain and heart tissues were taken for RNA extraction to perform RT-PCR analysis.

\subsection{Macroscopic and Microscopic Analysis}

Chicken embryos treated with ECL were examined under the stereomicroscope and compared with their matched controls. Angiogenesis of the chorioallantoic membrane (CAM) and the embryo was observed, and images were captured. Moreover, embryonic tissues were also inspected under the microscope with a special focus on brain, heart, and liver tissues as previously described [18,20].

\subsection{RNA Isolation and Reverse Transcription (RT)-PCR Analysis}

Total RNA was purified from brain, heart, and liver tissues of chicken embryos using the RNeasy Plus Mini Kit (Qiagen, Valencia, CA, USA) according to the manufacturer's instructions. cDNA synthesis and PCR amplification were performed using Invitrogen Superscript III One-Step RT-PCR System with Platinum ${ }^{\mathrm{TM}}$ Taq DNA Polymerase (Thermo Fisher Scientific, Mississauga, ON, Canada) according to the manufacturer's protocol.

RT-PCR amplification was performed using primer sets for activating transcription factor-3 (ATF-3), forkhead box-A2 (FOXA2), inhibin beta-A (INHBA), microtubule-associated protein RP/EB family member-2 (MAPRE-2), receptor-interacting serine-threonine kinase-1 (RIPK-1), serpin peptidase inhibitor-4 (SERPINA-4), and vascular endothelial growth factor-C (VEGF-C) (Table 1).

Table 1. Primer sets for ATF-3, FOXA2, INHBA, MAPRE-2, RIPK-1, SERPINA-4, and VEGF-C used for RT-PCR amplification.

\begin{tabular}{|c|c|}
\hline Gene Name & Primers \\
\hline \multirow{2}{*}{$A T F-3$} & $5^{\prime}$ - AAAAGCGAAGAAGGGAAAGG - 3' \\
\hline & 5' - ATACAGGTGGGCCTGTGAAG - 3' \\
\hline \multirow{2}{*}{ FOXA2 } & 5' - GACCTCTTCCCCTTCTACCG - 3' \\
\hline & $5^{\prime}$ - AGGTAGCAGCCGTTCTCAAA - 3' \\
\hline \multirow{2}{*}{ INHBA } & $5^{\prime}$ - GCCACCAAGAAACTCCATGT - 3' \\
\hline & $5^{\prime}$ - GCAACGTTTTCTTGGGTGTT - 3' \\
\hline \multirow{2}{*}{ MAPRE-2 } & $5^{\prime}$ - CAAAGGAGCCTTCCACAGAG - 3' \\
\hline & 5' - GTCACTTCTGATGGCAGCAA - 3' \\
\hline \multirow{2}{*}{ RIPK-1 } & 5' - CCGTACAGAATTGCAGCAGA - 3' \\
\hline & 5' - TTCCATTAGCACACGAGCTG - 3' \\
\hline \multirow{2}{*}{ SERPINA-4 } & $5^{\prime}$ - CCAGCAAAAGGGAAAATGAA - 3' \\
\hline & 5' - CACCACTGATGCCAGAGAGA - 3' \\
\hline \multirow{2}{*}{$V E G F-C$} & 5' - AGGGAACACTCCAGCTCTGA - 3' \\
\hline & $5^{\prime}$ - CТССАААСТСТТТССССАСА - 3' \\
\hline \multirow{2}{*}{ GAPDH } & $5^{\prime}$ - CCTCTCTGGCAAAGTCCAAG - 3' \\
\hline & $5^{\prime}$ - CATCTGCCCATTTGATGTTG - 3' \\
\hline
\end{tabular}

GAPDH primers were used as an internal control. In order to obtain a relative quantification of gene expressions, images acquired from RT-PCR were analyzed using ImageJ software 1.52k (National Institute of Mental Health, Bethesda, MD, USA.) [21]. The intensity of the bands relative to the GAPDH bands were used to calculate a relative expression of genes in each of the analyzed tissues (brain, heart, and liver). 


\subsection{Angiogenesis Quantification, Statistical and Survival Analysis}

To test the difference in angiogenesis, three parameters (vessel area, number of junctions, and total vessel length) were quantified using AngioTool program version $0.6 \mathrm{a}$ as described elsewhere [22].

A simple $2 \times 2$ chi square table was used to compare the difference in survival between subjects treated with e-cigarettes and their matched controls. Kaplan-Meier survival analysis curves for the two groups were plotted and compared using log-rank test. Normal distribution of all measurements was tested using histograms and the Shapiro-Wilk test. Means of normally distributed data were compared using T-test, while non-normally distributed data were compared using Mann-Whitney U-test. Statistical Package for Social Sciences (SPSS) 64-bit version 23 was used to carry out the aforementioned tests. All tests were two-tailed, and results were considered statistically significant if $p$-values were $<0.05$.

\section{Results}

A total of 72 chicken embryos were treated at 3 days of incubation with either ECL or clear buffer solution and observed for 5 days in order to explore the outcome of ECL on survival during embryonic development. The embryos were divided based on the treatment concentration of ECL into $60 \mu \mathrm{g}$, $30 \mu \mathrm{g}$, and control with 30,31, and 11 embryos, respectively. A significant difference was observed in the survival as $76 \%$ of embryos treated with $60 \mu \mathrm{g}$ ECL died, compared to $64 \%$ in the $30 \mu \mathrm{g}$ ECL group and $9 \%$ in the control group $(p<0.001$; Table 2$)$.

Table 2. Number of embryos used in survival analysis and percentage that died after 5 days. We note that approximately $70 \%$ of e-cigarette liquid (ECL)-treated embryos die 5 days after treatment. The embryos were exposed to ECL at 3 days of incubation as described in the methods section. Chi-square test was used for comparison $(p<0.001)$.

\begin{tabular}{ccc}
\hline Embryos & Number of Cases & $\begin{array}{c}\text { Number of Embryos Dead } \\
\text { Before 8 Days of Incubation (\%) }\end{array}$ \\
\hline $\mathbf{6 0} \boldsymbol{\mu g}$ ECL & 30 & $23(76)$ \\
$\mathbf{3 0} \boldsymbol{\mu g}$ ECL & 31 & $20(64)$ \\
Control & 11 & $1(9)$ \\
\hline
\end{tabular}

Kaplan-Meier survival analysis was used to compare the number of dead embryos. Most of the embryos in the treatment groups died in the first $24 \mathrm{~h}$ of treatment especially in the higher concentration group. This significant difference was also evident when comparing the survival curves of the groups using log-rank test $(p=0.001$; Figure 1$)$.

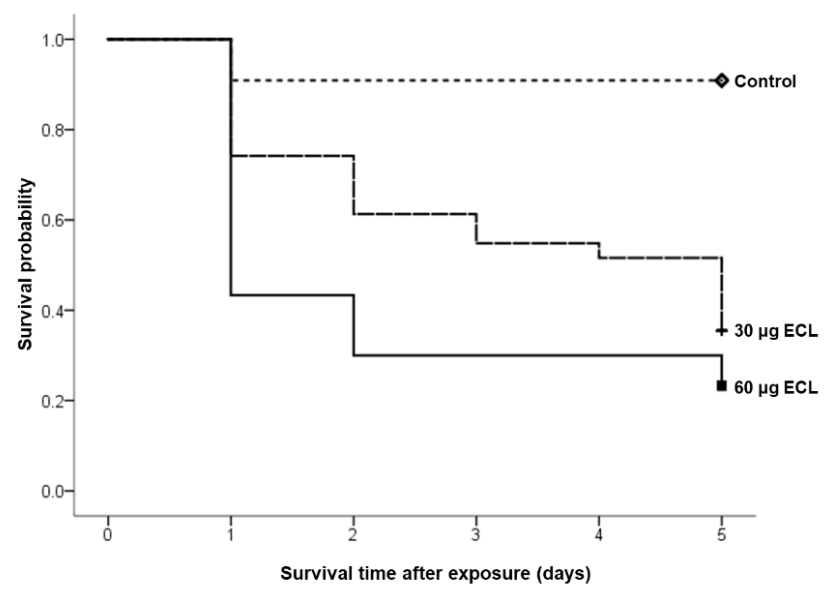

Figure 1. Survival analysis of ECL-treated embryos and their matched controls. It is clear that ECL significantly decreases the survival probability of exposed embryos in comparison with their control $(p=0.001)$. 
Microscopic and macroscopic examination of surviving embryos was performed with a special focus on heart, brain, and liver tissues. No morphological changes were observed in the treatment group. Additionally, samples were taken from these tissues to examine the expression of key regulator genes of embryogenesis. RT-PCR was performed to explore the effects of ECL on the gene expression patterns of ATF-3, FOXA2, INHBA, MAPRE-2, RIPK-1, SERPINA-4, and VEGF-C in brain, heart, and liver tissues of the embryos. Our results showed that ATF-3, FOXA2, INHBA, MAPRE-2, and RIPK-1 were upregulated in ECL-treated embryos compared to their matched controls. On the other hand, SERPINA-4 and VEGF-C genes were downregulated in the ECL-treated subjects. These results were statistically significant and consistent in all three different tissues (Figure 2).

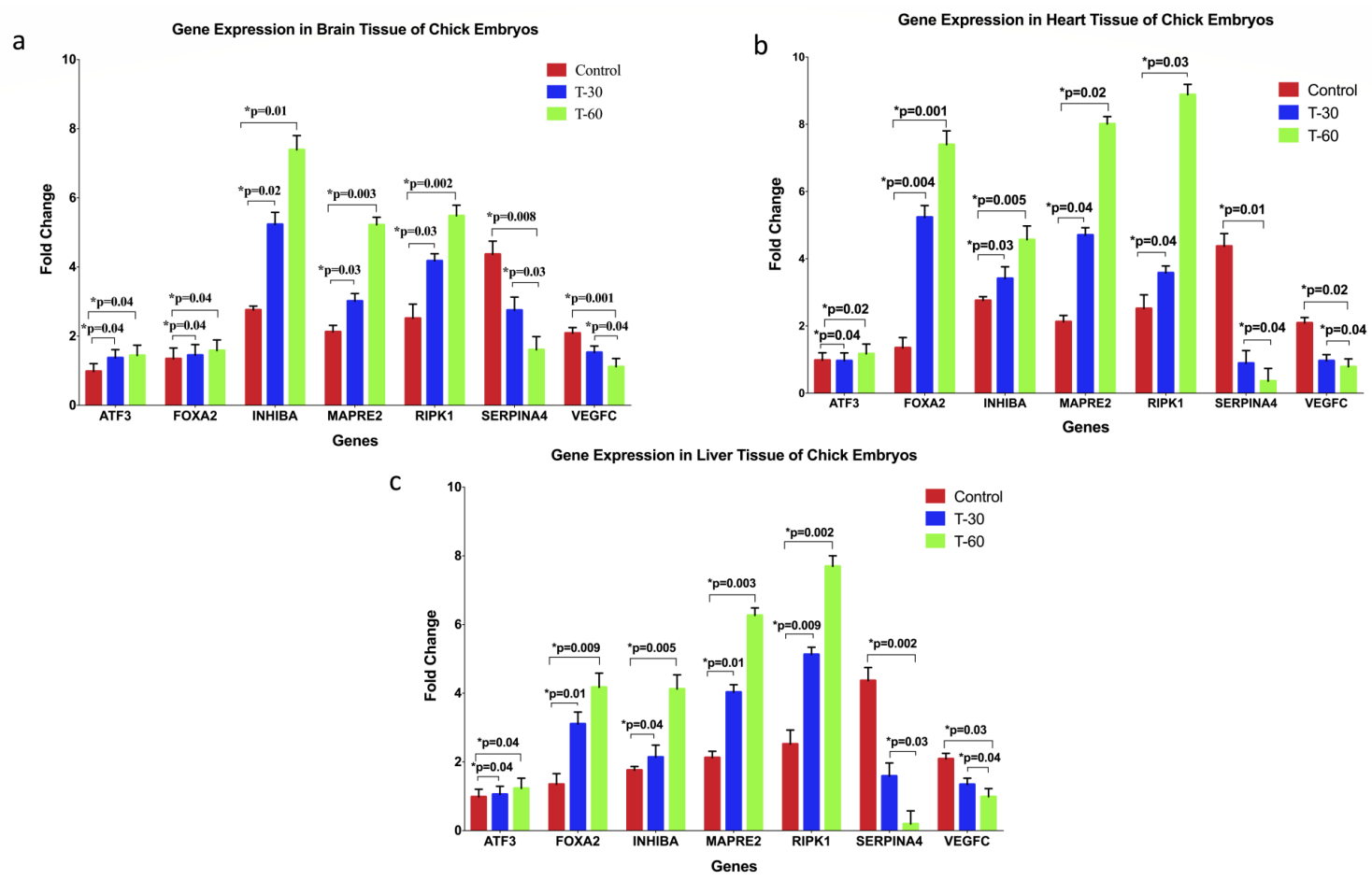

Figure 2. RT-PCR analysis of ATF-3, FOXA2, INHBA, MAPRE-2, RIPK-1, SERPINA-4, and VEGF-C genes in brain (A), heart (B), and liver (C) of chicken embryos at 8 days of incubation. We observed that ECL induced an upregulation of ATF-3, FOXA2, INHBA, MAPRE-2, and RIPK-1 and downregulation of SERPINA-4 and VEGF-C in comparison with control tissues. The embryos were exposed to ECL at 3 days of incubation as described in the Materials and Methods section.

Angiogenesis of the CAM and the embryo was examined in 25 chicken embryos (8 exposed to $60 \mu \mathrm{g}$ ECL and 12 to $30 \mu \mathrm{g}$ ECL in addition to 5 control samples). Embryos were exposed at the 5 th day of incubation as we were aiming for optimal vascularization time. The embryos were examined 24 and $48 \mathrm{~h}$ after exposure. The embryos showed a decrease in all assessed parameters in a dose-effect manner. The number of junctions and total vessel length were significantly less in embryos treated with low or high concentration of ECL. Conversely, the vessel area was significantly less with high ECL concentration but not with the lower concentration $(p=0.052$, Figure 3$)$. 


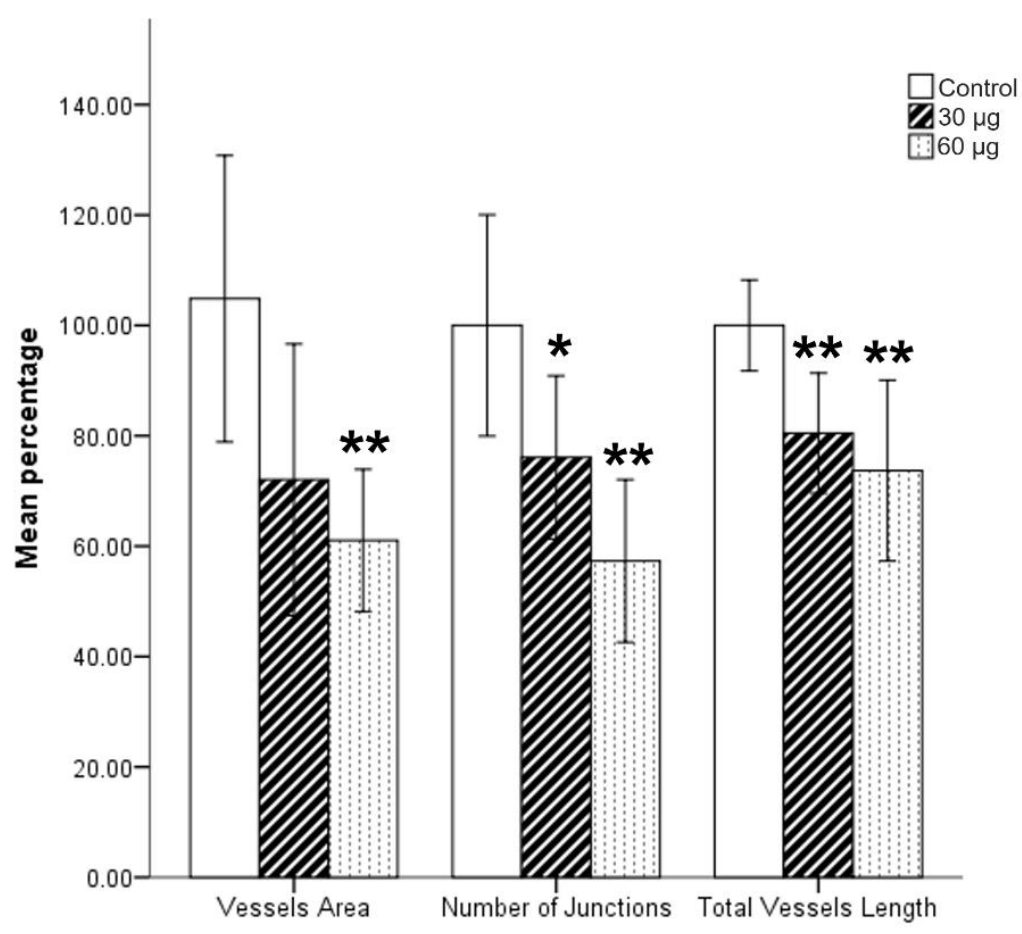

Figure 3. Quantification of chorioallantoic membrane (CAM) angiogenesis of chicken embryos at seven days of incubation using AngioTool program. Blood vessel area, number of junctions, and total vessel length were compared between ECL-treated CAMs and their matched controls. It is clear, from this analysis, that ECL inhibits angiogenesis of the CAM in ECL-treated embryos in comparison with untreated ones. Embryos were exposed to ECL at 5 days of incubation as illustrated in the Methods section. Total samples, $n=25{ }^{*} p<0.05 ;{ }^{* *} p<0.01$.

\section{Discussion}

Despite the rapidly increasing worldwide consumption of e-cigarettes, their safety remains largely unproven. Hence, the current study aimed to investigate the effects of ECL on early embryogenesis using a chicken embryo model. To our knowledge, no studies investigated the effects of ECL on embryo survival and its effects on the early stages of embryogenesis including angiogenesis. Therefore, we decided to use the chicken embryo model as it has been used to study similar parameters in previous studies [18,23]. Our study revealed that exposure to chemicals in e-cigarettes significantly decreased the survival likelihood in chicken embryos as $76 \%$ of chicken embryos in the $60 \mu \mathrm{g}$ ECL group died compared to only $11 \%$ from their matched controls. This finding is consistent with the current literature on the effects of traditional cigarette smoking on embryo survival [23]. Other studies have elucidated the harmful effects of ECL on embryogenesis albeit by using different animal models. It was shown that exposure to e-cigarette aerosols inhibited cardiac transcription factors and hence cardiac development in a zebrafish model and in human embryonic stem cells [24]. It was also shown that exposing zebrafish embryos to 1,2 propanediol, which is a major component of e-cigarettes, increased the incidence of string heart and yolk sac edema [25].

Currently, there is no consensus on the exact toxic mechanisms involved in ECS-related systematic dysfunction and cellular damage. Nonetheless, recent experimental and clinical data shows that ECS increases inflammation, inflammatory mediators, and oxidative stress $[13,14]$. The data also suggest that ECS may potentiate mechanisms for initiating cellular dysfunction as well as significantly altering genetic expression and enhancing mutations [26]. Human lung cells, for instance, were shown to develop oxidative toxicity and morphological changes in response to aerosols produced by vaporizing e-cigarette liquids in several studies $[13,14]$. Other investigations have also reported cytotoxic effects on cultured cardiomyoblasts. Interestingly, it was found that this effect is mainly 
associated with the byproducts used in flavorings rather than with nicotine itself [9]. In addition, exposure to e-cigarette smoke is reported to result in an impaired immunological response [27]. Additionally, a recent investigation conducted on respiratory epithelium has shown that e-cigarettes might lead to a decreased expression of immune-related genes similar to that caused by cigarettes and water-pipe smoking through inactivation of transcription factors, such as Early Growth Response 1 (EGR1) [27]. Other studies have shown that ECS affects the immune system by impairing pulmonary antibacterial and antiviral defenses. In in vivo experiments, mice that were exposed to e-cigarette liquid vapor elicited severely defective pulmonary bacterial clearance after being infected with Streptococcus pneumoniae. Reduced phagocytosis by alveolar macrophages is thought to be the key event in the pathogenesis of airway diseases [28]. Moreover, our study showed that ECL negatively affected the angiogenesis in the CAM of ECL-treated embryos in a dose-effect manner. Our findings may be explained by the increase in oxidative stress and inflammation known to be caused by ECS in exposed embryos [29]. These findings implicate the extensive toxic effects of ECL exposure on embryogenesis and suggest that expecting mothers should be warned of the effects ECS could have. This is also consistent with relevant literature studying the effects of traditional cigarettes on angiogenesis in embryos [30].

Lastly, our study demonstrated that ECL exposure also increased gene expression of ATF-3, FOXA2, INHBA, MAPRE-2, and RIPK-1 and decreased SERPINA-4 and VEGF-C in the hearts, brains and livers of chicken embryos. Thus, it is clear that ECL can affect the physiology of exposed organisms via the deregulation of key genes and modulation of essential transcription factors such as ATF-3, which represents one of the key regulators of cell proliferation [31], as well as RIPK-1, which regulates cellular death and apoptosis [32]. Furthermore, downregulation of VEGF-C expression could explain the effect of ECL on angiogenesis. These data are consistent with our previous work on water-pipe smoking and single-walled carbon nanotubes (SWCNTs) on embryogenesis where we demonstrated the dramatic effects and cytotoxicity of carbon and nicotine on similar genes and how they affect embryogenesis $[18,20]$. In fact, only few data are available on the effects of ECL on gene expression. A study conducted by Canistro et al. (2017) described the toxicological and mutagenic effects of e-cigarettes on genes, which may lead to cancer. It was discovered that e-cigarettes damage DNA not only at the chromosomal levels as characterized by strand breaks, but also at a genetic level since they were shown to cause point mutations, particularly among younger consumers [26]. Furthermore, they also found that e-cigarettes possess a potent promoting effect on phase-I carcinogen-bioactivating enzymes, including activators of polycyclic aromatic hydrocarbons, in addition to DNA oxidation to 8-hydroxy-2'-deoxyguanosine [26].

The ECL generally consists of nicotine, flavorings, and a humectant [33]. Although the harmful health effects of nicotine are well known, it is believed that its effects are nascent when delivered as an aerosol [33]. Furthermore, it has been indicated that inhaling ECL and holding it for a longer time, helps to develop a stronger vape; however, this increases the amount of pulmonary deposition resulting in higher drug absorption in the blood as well as toxicity [34]. A previous study, evaluated the presence of toxins in both ECL and aerosols; they found the presence of diacetyl and acetyl propionyl in large quantities in ECL, thus, exposing users to higher than recommended safety levels of these toxins [35]. Moreover, in comparison to cigarette smoke extract, toxic effect of ECL is comparatively less $[9,36,37]$. In addition, ECL was used to test its effect on inflammatory response and innate immune defense against human rhinovirus infection in vitro and in vivo [38]. Additionally, another in vivo study in asthmatic mice models used ECL to study its effect on respiratory health; after 10 weeks, ECL elevated pro-inflammatory cytokine levels and airway hyper-responsiveness to methacholine challenge [39]. The health effects observed in the study were due to increased sensitivity of "asthmatic" lungs to inhaled respiratory irritants and not solely due to ECL effect. These observations led us to use ECL over aerosol and hence the embryos were treated with ECL [39].

Although e-cigarettes contain less amount of nicotine, we believe that other components available in ECL, especially flavorings, contribute to the cytotoxic effect of ECL demonstrated by our study. This 
is supported by the study published by Omaiye et al. (2019) that assessed the effect of eight commonly used flavorings in different concentrations and showed a concentration-response toxic effect of all types [40]. Furthermore, heavy metals such as Mn, Ni, and Zn in ECL could potentially contribute to this toxicity [8]. Finally, volatile organic compounds such as acrylamide could play a role in toxicity since it was shown to be a reproductive toxicant [41].

\section{Conclusions}

In our study, we reveal, for the first time, that ECL has dramatic adverse effects on the early stage of the normal embryonic development. This effect, which includes hindered angiogenesis and even death, is mainly due to the effect of ECL on the key regulator genes of embryogenesis that are ATF-3, FOXA2, INHBA, MAPRE-2, RIPK-1, SERPINA-4, and VEGF-C. Although our study clearly defines the toxic outcomes of ECL, more studies are needed to further elucidate the mechanism by which ECS affects embryogenesis and other aspects of human pathologies, as well as the embryonic response to ECL using non-lethal doses.

Author Contributions: These authors contributed equally: H.A. and A.A. Conceptualization: A.-E.A.M.; methodology: H.A., U.B.R., L.A., and I.G.; data curation: H.A., A.A., and I.G.; writing: A.A. and I.G.; writing-review and editing: S.V., A.M., and A.-E.A.M.; supervision: A.-E.A.M. and S.V.; funding acquisition: A.-E.A.M. All authors have read and agreed to the published version of the manuscript.

Funding: A-E-A.M's lab is supported by grants from the Qatar University: QUHI-CMED-19/20-1, GCC \# 2017-002 QU/KU, and QUST-1-CMED-2020-2.

Acknowledgments: The authors would like to thank A. Kassab for her critical reading of the manuscript.

Conflicts of Interest: The authors declare no conflict of interest. The funders had no role in the design of the study; in the collection, analyses, or interpretation of data; in the writing of the manuscript; or in the decision to publish the results.

\section{References}

1. WHO. Tobacco. Available online: https://www.who.int/news-room/fact-sheets/detail/tobacco (accessed on 1 December 2019).

2. Gowing, L.R.; Ali, R.L.; Allsop, S.; Marsden, J.; Turf, E.E.; West, R.; Witton, J. Global statistics on addictive behaviours: 2014 status report. Addiction 2015, 110, 904-919. [CrossRef] [PubMed]

3. Onor, I.O.; Stirling, D.L.; Williams, S.R.; Bediako, D.; Borghol, A.; Harris, M.B.; Darensburg, T.B.; Clay, S.D.; Okpechi, S.C.; Sarpong, D.F. Clinical Effects of Cigarette Smoking: Epidemiologic Impact and Review of Pharmacotherapy Options. Int. J. Environ. Res. Public Health 2017, 14, 1147. [CrossRef] [PubMed]

4. Caponnetto, P.; Campagna, D.; Papale, G.; Russo, C.; Polosa, R. The emerging phenomenon of electronic cigarettes. Expert Rev. Respir. Med. 2012, 6, 63-74. [CrossRef] [PubMed]

5. Lempert, L.K.; Grana, R.; Glantz, S.A. The importance of product definitions in US e-cigarette laws and regulations. Tob. Control 2016, 25, e44-e51. [CrossRef]

6. Laverty, A.A.; Filippidis, F.T.; Vardavas, C.I. Patterns, trends and determinants of e-cigarette use in 28 European Union Member States 2014-2017. Prev. Med. 2018, 116, 13-18. [CrossRef]

7. Goniewicz, M.L.; Knysak, J.; Gawron, M.; Kosmider, L.; Sobczak, A.; Kurek, J.; Prokopowicz, A.; Jablonska-Czapla, M.; Rosik-Dulewska, C.; Havel, C.; et al. Levels of selected carcinogens and toxicants in vapour from electronic cigarettes. Tob. Control 2014, 23, 133-139. [CrossRef]

8. Olmedo, P.; Goessler, W.; Tanda, S.; Grau-Perez, M.; Jarmul, S.; Aherrera, A.; Chen, R.; Hilpert, M.; Cohen, J.E.; Navas-Acien, A.; et al. Metal Concentrations in e-Cigarette Liquid and Aerosol Samples: The Contribution of Metallic Coils. Environ. Health Perspect. 2018, 126, 027010. [CrossRef]

9. Farsalinos, K.E.; Romagna, G.; Allifranchini, E.; Ripamonti, E.; Bocchietto, E.; Todeschi, S.; Tsiapras, D.; Kyrzopoulos, S.; Voudris, V. Comparison of the cytotoxic potential of cigarette smoke and electronic cigarette vapour extract on cultured myocardial cells. Int. J. Environ. Res. Public Health 2013, 10, 5146-5162. [CrossRef]

10. Hua, M.; Talbot, P. Potential health effects of electronic cigarettes: A systematic review of case reports. Prev. Med. Rep. 2016, 4, 169-178. [CrossRef] 
11. Benowitz, N.L.; Fraiman, J.B. Cardiovascular effects of electronic cigarettes. Nat. Rev. Cardiol. 2017, 14, 447-456. [CrossRef]

12. Hess, I.M.; Lachireddy, K.; Capon, A. A systematic review of the health risks from passive exposure to electronic cigarette vapour. Public Health Res. Pract. 2016, 26, e2621617. [CrossRef] [PubMed]

13. Lerner, C.A.; Sundar, I.K.; Yao, H.; Gerloff, J.; Ossip, D.J.; McIntosh, S.; Robinson, R.; Rahman, I. Vapors produced by electronic cigarettes and e-juices with flavorings induce toxicity, oxidative stress, and inflammatory response in lung epithelial cells and in mouse lung. PLoS ONE 2015, 10, e0116732. [CrossRef] [PubMed]

14. Scheffler, S.; Dieken, H.; Krischenowski, O.; Forster, C.; Branscheid, D.; Aufderheide, M. Evaluation of E-cigarette liquid vapor and mainstream cigarette smoke after direct exposure of primary human bronchial epithelial cells. Int. J. Environ. Res. Public Health 2015, 12, 3915-3925. [CrossRef] [PubMed]

15. Chen, H.; Li, G.; Chan, Y.L.; Chapman, D.G.; Sukjamnong, S.; Nguyen, T.; Annissa, T.; McGrath, K.C.; Sharma, P.; Oliver, B.G. Maternal E-Cigarette Exposure in Mice Alters DNA Methylation and Lung Cytokine Expression in Offspring. Am. J. Respir. Cell Mol. Biol. 2018, 58, 366-377. [CrossRef]

16. Nguyen, T.; Li, G.E.; Chen, H.; Cranfield, C.G.; McGrath, K.C.; Gorrie, C.A. Maternal E-Cigarette Exposure Results in Cognitive and Epigenetic Alterations in Offspring in a Mouse Model. Chem. Res. Toxicol. 2018, 31, 601-611. [CrossRef]

17. Raez-Villanueva, S.; Ma, C.; Kleiboer, S.; Holloway, A.C. The effects of electronic cigarette vapor on placental trophoblast cell function. Reprod. Toxicol. 2018, 81, 115-121. [CrossRef] [PubMed]

18. Ashour, A.A.; Haik, M.Y.; Sadek, K.W.; Yalcin, H.C.; Bitharas, J.; Aboulkassim, T.; Batist, G.; Yasmeen, A.; Al Moustafa, A.E. Substantial Toxic Effect of Water-Pipe Smoking on the Early Stage of Embryonic Development. Nicotine Tob. Res. 2018, 20, 502-507. [CrossRef] [PubMed]

19. Sadek, K.W.; Haik, M.Y.; Ashour, A.A.; Baloch, T.; Aboulkassim, T.; Yasmeen, A.; Vranic, S.; Zeidan, A.; Al Moustafa, A.-E. Water-pipe smoking promotes epithelial-mesenchymal transition and invasion of human breast cancer cells via ERK1/ERK2 pathways. Cancer Cell Int. 2018, 18, 180. [CrossRef] [PubMed]

20. Roman, D.; Yasmeen, A.; Mireuta, M.; Stiharu, I.; Al Moustafa, A.E. Significant toxic role for single-walled carbon nanotubes during normal embryogenesis. Nanomedicine 2013, 9, 945-950. [CrossRef]

21. Schneider, C.A.; Rasband, W.S.; Eliceiri, K.W. NIH Image to ImageJ: 25 years of image analysis. Nat. Methods 2012, 9, 671-675. [CrossRef]

22. Zudaire, E.; Gambardella, L.; Kurcz, C.; Vermeren, S. A computational tool for quantitative analysis of vascular networks. PLoS ONE 2011, 6, e27385. [CrossRef] [PubMed]

23. Ejaz, S.; Ejaz, A.; Sohail, A.; Lim, C.W. Vascular and morphogenetic abnormalities associated with exposure of cigarette smoke condensate during chicken and murine embryogenesis. Biomed. Environ. Sci. 2010, 23, 305-311. [CrossRef]

24. Palpant, N.J.; Hofsteen, P.; Pabon, L.; Reinecke, H.; Murry, C.E. Cardiac development in zebrafish and human embryonic stem cells is inhibited by exposure to tobacco cigarettes and e-cigarettes. PLOS ONE 2015, 10, e0126259. [CrossRef] [PubMed]

25. Massarsky, A.; Abdel, A.; Glazer, L.; Levin, E.D.; Di Giulio, R.T. Exposure to 1,2-Propanediol Impacts Early Development of Zebrafish (Danio rerio) and Induces Hyperactivity. Zebrafish 2017, 14, 216-222. [CrossRef]

26. Canistro, D.; Vivarelli, F.; Cirillo, S.; Babot Marquillas, C.; Buschini, A.; Lazzaretti, M.; Marchi, L.; Cardenia, V.; Rodriguez-Estrada, M.T.; Lodovici, M.; et al. E-cigarettes induce toxicological effects that can raise the cancer risk. Sci. Rep. 2017, 7, 2028. [CrossRef]

27. Martin, E.M.; Clapp, P.W.; Rebuli, M.E.; Pawlak, E.A.; Glista-Baker, E.; Benowitz, N.L.; Fry, R.C.; Jaspers, I. E-cigarette use results in suppression of immune and inflammatory-response genes in nasal epithelial cells similar to cigarette smoke. Am. J. Physiol. Lung Cell. Mol. Physiol. 2016, 311, L135-L144. [CrossRef]

28. Sussan, T.E.; Gajghate, S.; Thimmulappa, R.K.; Ma, J.; Kim, J.H.; Sudini, K.; Consolini, N.; Cormier, S.A.; Lomnicki, S.; Hasan, F.; et al. Exposure to electronic cigarettes impairs pulmonary anti-bacterial and anti-viral defenses in a mouse model. PLOS ONE 2015, 10, e0116861. [CrossRef]

29. Chatterjee, S.; Tao, J.Q.; Johncola, A.; Guo, W.; Caporale, A.; Langham, M.C.; Wehrli, F.W. Acute exposure to e-cigarettes causes inflammation and pulmonary endothelial oxidative stress in nonsmoking, healthy young subjects. Am. J. Physiol. Lung Cell. Mol. Physiol. 2019, 317, L155-L166. [CrossRef]

30. Ejaz, S.; Ashraf, M.; Nawaz, M.; Lim, C.W.; Kim, B. Cigarette smoke condensate and total particulate matter severely disrupts physiological angiogenesis. Food Chem. Toxicol. 2009, 47, 601-614. [CrossRef] 
31. Song, Q.; Chen, Q.; Wang, Q.; Yang, L.; Lv, D.; Jin, G.; Liu, J.; Li, B.; Fei, X. ATF-3/miR-590/GOLPH3 signaling pathway regulates proliferation of breast cancer. BMC Cancer 2018, 18, 255. [CrossRef]

32. Dondelinger, Y.; Delanghe, T.; Rojas-Rivera, D.; Priem, D.; Delvaeye, T.; Bruggeman, I.; Van Herreweghe, F.; Vandenabeele, P.; Bertrand, M.J.M. MK2 phosphorylation of RIPK1 regulates TNF-mediated cell death. Nat. Cell Biol. 2017, 19, 1237-1247. [CrossRef] [PubMed]

33. National Academies of Sciences, Engineering, and Medicine; Health and Medicine Division; Board on Population Health and Public Health Practice; Committee on the Review of the Health Effects of Electronic Nicotine Delivery Systems. Public Health Practice; Committee on the Review of the Health Effects of Electronic Nicotine Delivery Systems. Public Health Consequences of E-Cigarettes. In E-Cigarette Devices, Uses, and Exposures; Eaton, D.L., Kwan, L.Y., Stratton, K., Eds.; National Academies Press (US): Washington, DC, USA, 2018; Volume 3.

34. Mulder, H.A.; Patterson, J.L.; Halquist, M.S.; Kosmider, L.; Turner, J.B.M.; Poklis, J.L.; Poklis, A.; Peace, M.R. The Effect of Electronic Cigarette User Modifications and E-liquid Adulteration on the Particle Size Profile of an Aerosolized Product. Sci. Rep. 2019, 9, 10221. [CrossRef] [PubMed]

35. Farsalinos, K.E.; Kistler, K.A.; Gillman, G.; Voudris, V. Evaluation of electronic cigarette liquids and aerosol for the presence of selected inhalation toxins. Nicotine Tob. Res. 2015, 17, 168-174. [CrossRef] [PubMed]

36. Romagna, G.; Allifranchini, E.; Bocchietto, E.; Todeschi, S.; Esposito, M.; Farsalinos, K.E. Cytotoxicity evaluation of electronic cigarette vapor extract on cultured mammalian fibroblasts (ClearStream-LIFE): Comparison with tobacco cigarette smoke extract. Inhal. Toxicol. 2013, 25, 354-361. [CrossRef]

37. Misra, M.; Leverette, R.D.; Cooper, B.T.; Bennett, M.B.; Brown, S.E. Comparative in vitro toxicity profile of electronic and tobacco cigarettes, smokeless tobacco and nicotine replacement therapy products: E-liquids, extracts and collected aerosols. Int. J. Environ. Res. Public Health 2014, 11, 11325-11347. [CrossRef]

38. Wu, Q.; Jiang, D.; Minor, M.; Chu, H.W. Electronic cigarette liquid increases inflammation and virus infection in primary human airway epithelial cells. PLoS ONE 2014, 9, e108342. [CrossRef]

39. Lim, H.B.; Kim, S.H. Inhallation of e-Cigarette Cartridge Solution Aggravates Allergen-induced Airway Inflammation and Hyper-responsiveness in Mice. Toxicol. Res. 2014, 30, 13-18. [CrossRef]

40. Omaiye, E.E.; McWhirter, K.J.; Luo, W.; Pankow, J.F.; Talbot, P. High-Nicotine Electronic Cigarette Products: Toxicity of JUUL Fluids and Aerosols Correlates Strongly with Nicotine and Some Flavor Chemical Concentrations. Chem. Res. Toxicol. 2019, 32, 1058-1069. [CrossRef]

41. Manson, J.; Brabec, M.J.; Buelke-Sam, J.; Carlson, G.P.; Chapin, R.E.; Favor, J.B.; Fischer, L.J.; Hattis, D.; Lees, P.S.; Perreault-Darney, S.; et al. NTP-CERHR expert panel report on the reproductive and developmental toxicity of acrylamide. Birth Defects Res. B Dev. Reprod. Toxicol. 2005, 74, 17-113. [CrossRef] 